\title{
Recurrent Submandibular Gland Undifferentiated Carcinoma
}

National Cancer Institute

\section{Source}

National Cancer Institute. Recurrent Submandibular Gland Undifferentiated Carcinoma. NCI Thesaurus. Code C153812.

The reemergence of submandibular gland undifferentiated carcinoma after a period of remission. 